\title{
Induction of labour: eternal controversy
}

\begin{abstract}
According to WHO, 25\% of all deliveries are induced in developed countries. There are many controversies and multiple guides to induction of labour (IOL) are used in different hospitals. There are social or maternofetal indications to IOL. The way to perform the IOL depends on cervical status. Currently, prostaglandins are considered the most effective method to IOL (delivery before 24hours). Depends on each patient, it is recommended misoprostol or dinoprostone. For cases with contraindications for prostaglandins, mechanical methods (Foley catheter or double balloon intracervical catheter) are good alternatives. In any case, some special circumstances (twins' pregnancies, women with previous caesarean...) must been considered. According to perinatal outcomes, both methods are similar. Although prostaglandins are more costeffective method, women are most satisfied with mechanical methods.
\end{abstract}

Keywords: labour induction, misoprostol, double-balloon catheter, foley catheter, dinoprostone
Volume 3 Issue 3 - 2017

\author{
Jorge Duro Gómez, Camil Castelo-Branco, \\ José Eduardo Arjona Berral \\ Department of Gynecology and Obstetrics, Reina Sofía \\ University Hospital, Spain
}

\begin{abstract}
Correspondence: Camil Castelo-Branco, Department of Gynecology and Obstetrics, Institut Clinic of Gynecology, Obstetrics and Neonatology, Hospital Clinic,Villarroel 170, 08036-Barcelona, Spain, Tel + 349322754 36, Fax + 3993227 93 25, Email castelobranco@ub.edu
\end{abstract}

Received: August 28, 2017| Published: December 07, 2017

\section{Introduction}

Induction of labour (IOL) is one of the most frequently used techniques in current obstetrics. According to WHO, 25\% of all deliveries in developed countries are induced. Generally, developing countries have lower rates of IOL. ${ }^{1}$ The goal is to get the advancement of the delivery before its spontaneous evolution. There are many controversies on this procedure and; therefore, dissimilar guides are used in different hospitals. In addition, it is not a harmless technique and for this reason it is important to have adequate protocols in order to optimize resources and diminish risks. ${ }^{2}$ In this review, we present the main controversies related to IOL.

\section{What are the indications for induction of la- bour?}

We have two types of indications. First, social or geographical indication. Maternal anxiety or the risks of childbirth precipitated in rural areas are some of its reasons. According to American College of Obstetricians and Gynaecologist, this is a not appropriate indication. ${ }^{3} \mathrm{An}$ adequate program could reduce induction by this reason in different hospitals. ${ }^{4}$ There is no consensus about if this practice increases the rate of caesarean section, ${ }^{5,6}$ however it could reduce the risk of stillbirth, neonatal care and macrosomia. ${ }^{7-9}$

On the other hand, we have IOL for maternofoetal reasons. Premature rupture of membranes, post-term pregnancy, hypertension, intrauterine growth restriction, oligoamnios or maternal disease are some of most common indications..$^{10}$ In these cases, it is essential to establish updated and consensual actuation protocols for IOL.

\section{How can induction of labour be done?}

The way to perform the IOL depends fundamentally on the cervical status. For Bishop $<6$ it is advised cervical ripening before stimulation with oxytocin. ${ }^{11}$ Currently, prostaglandins are considered the most effective method (delivery before 24hours). ${ }^{12,13}$ Other alternatives such as mechanical methods (Foley catheter, double balloon intracervical catheter) have also demonstrated efficacy and safety for IOL. ${ }^{14-16}$

Multiple prostaglandin regimens have been shown to improve unfavourable cervix. ${ }^{17,18}$ Vaginal misoprostol has demonstrated superiority versus dinoprostone with similar safety. ${ }^{19,20}$ Misoprostol can also be administered orally with a rapid systemic spike and rapid decrease in the blood concentration. ${ }^{21,22}$ If we compared with vaginal administration, it is slower but has better perinatal results and lower rate caesarean. ${ }^{23}$

However, misoprostol has some side effects. Tachysystole is the most frequent. For this reason, in case of high risk of tachysystole (eg. polyhydramnios), dinoprostone could be a better alternative. There are a several preparations marketed as cervidil ${ }^{\circledR}$, prepidil ${ }^{\circledR}$ or dinoprostone vaginal insert device ${ }^{\circledR}$. The last one, as advantage, can be removed in case of hyperstimulation and seem to be a safe and effective option in patients with previous caesarean section. ${ }^{24}$

In general, mechanical methods have an efficacy similar to prostaglandins, but with fewer deliveries within the first 24hours and a similar rate of cesarean section..$^{25,26}$ According to some studies, double balloon intracervical catheter seems to be more effective than Foley catheter. ${ }^{27,28}$ Application of tension to these procedures does not improve results. ${ }^{29}$ In addition, higher doses oxytocin may be necessary with mechanical methods compared to prostaglandins. ${ }^{16}$ In spite of these limitations, mechanical methods could be especially useful in patients with risk of hyperstimulation or when prostaglandins are contraindicated (eg. previous uterine surgery). ${ }^{30}$ Although, in case of previous caesarean section, we must always keep in mind that IOL is associated with an increased risk of uterine rupture respect to spontaneous delivery. ${ }^{31}$ Controversy exists on the increased risk of maternofoetal infections with mechanical methods. According to some studies, it does not happen when there is no premature rupture of membranes. ${ }^{32}$

Selecting the method several special circumstances should be considered. First, in women with hypertension during pregnancy prostaglandins are more effective than Foley catheter with similar rate of hyperstimulation..$^{33}$ Second, for obese patients prostaglandins and mechanical methods have a similar efficacy. And third, in case of twin pregnancy, IOL is considered a safe technique although it is associated an increased risk of caesarean ${ }^{34-36}$ independently of method that has been used Mei-Dan E. ${ }^{37}$ Due to the risk of hyperstimulation, 
dinoprostone vaginal insert device or mechanical methods for unfavourable cervix in case of twin pregnancies are recommended.

An important fact related to the patient is the comfort and satisfaction with the IOL methods. Although some patients refer discomfort with the mechanical methods especially at the time of insertion; women have a high degree of satisfaction with these methods. ${ }^{38,39}$

It is controversial if the sequential use of catheters and prostaglandins has a greater number of deliveries in first 24 hours. ${ }^{40,41}$ However, recent data suggest that with the application of Foley catheter plus oxytocin or prostaglandins an increased number of deliveries in first 24 hours is achieved. ${ }^{42-44}$

Regarding perinatal outcomes and related to spontaneous labour, IOL is associated with more maternal complications and worse perinatal results ${ }^{45}$ with independence of the method used Duro-Gómez J. ${ }^{46}$ Finally, for favourable Bishop $(\geq 6)$ early amniotomy prior to oxytocin stimulation reduces the interval to delivery. ${ }^{47}$

\section{What is the most cost-effective method?}

The factors that most influence the cost are, the Bishop score, previous deliveries, IOL due to maternal hypertension and caesarean section after IOL..$^{48,49}$ Considering these factors, misoprostol seems to be the most cost-effective option. ${ }^{2}$

\section{Conclusion}

There are a huge number of publications related to IOL showing a wide variability in the different methods of induction. This fact highlight the of further randomized studies to determine the most appropriate method. Moreover, each patient must be individualized and informed about risks and benefits of IOL.

\section{Acknowledgements}

None.

\section{Conflict of interest}

The authors declared there are no conflicts of interest in publication of this article.

\section{References}

1. WHO. Global survey on maternal and Perinatal Health. Induction of labour data. Geneva, Switzerland: World health Organization; 2010.

2. Duro-Gómez J, Garrido-Oyarzún MF, Rodríguez-Marín AB, et al. What can we do to reduce the associated cost in induction of labour of intrauterine growth restriction foetuses at term? A cost analysis study. Arch Gynecol Obstet. 2017.

3. American College of Obstetricians and Gynecologists. ACOG committee opinion no. 561: Nonmedically indicated early-term deliveries. Obstet Gynecol. 2013;121(4):911.

4. Oshiro BT, Kowalewski L, Sappenfield W, et al. A multistate quality improvement program to decrease elective deliveries before 39 weeks of gestation. Obstet Gynecol. 2013;121(5):1025-1031.

5. Parkes I, Kabiri D, Hants Y, et al. The indication for induction of labor impacts the risk of cesarean delivery. J Matern Fetal Neonatal Med. 2016;29(2):224-228.

6. Gülmezoglu AM, Crowther CA, Middleton P, et al. Induction of labour for improving birth outcomes for women at or beyond term. Cochrane Database Syst Rev. 2012;13(6):CD004945.
7. Mishanina E, Rogozinska E, Thatthi T, et al. Use of labour induction and risk of cesarean delivery: a systematic review and meta-analysis. CMAJ. 2014;186(9):665.

8. Rosenstein MG, Cheng YW, Snowden JM, et al. Risk of stillbirth and infant death stratified by gestational age. Obstet Gynecol. 2012;206(4):309. e1-309.e7.

9. Bailit JL, Grobman W, Zhao Y, et al. Nonmedically indicated induction vs expectant treatment in term nulliparous women. Am J Obstet Gynecol. 2015;212(1):103.e1-103.e7.

10. ACOG Committee on Practice Bulletins - Obstetrics. ACOG Practice Bulletin No. 107: Induction of labor. Obstet Gynecol. 2009;114(2 Pt 1):386-397.

11. Kelly AJ, Malik S, Smith L, et al. Vaginal prostaglandin (PGE2 and PGF2a) for induction of labour at term. Cochrane Database Syst Rev. 2009;4:CD003101.

12. Chen W, Xue J, Peprah MK, et al. A systematic review and network meta-analysis comparing the use of Foley catheters, misoprostol, and dinoprostone for cervical ripening in the induction of labour. BJOG. 2016;123(3):346-354.

13. Somirathne D, Goonewardene M, Dahanayake L. Three doses of oral misoprostol versus an intra-cervical Foley catheter for 24 hours for pre-induction cervical ripening in post- dated pregnancies: a randomized controlled trial. Ceylon Med J. 2017;62(2):77-82.

14. Ten Eikelder ML, Oude Rengerink K, Jozwiak M, et al. nduction of labour at term with oral misoprostol versus a Foley catheter (PROBAAT-II): a multicentre randomised controlled non-inferiority trial. Lancet. 2016;387(10028):1619-1628.

15. Gu N, Ru T, Wang Z, et al. Foley Catheter for Induction of Labor at Term: An Open-Label, Randomized Controlled Trial. PLoS One. 2015;10(8):e0136856.

16. Løkkegaard E, Lundstrøm M, Kjaer MM, et al. Prospective multi-centre randomised trial comparing induction of labour with a double-balloon catheter versus dinoprostone. J Obstet Gynaecol. 2015;35(8):797-802.

17. Thomas J, Fairclough A, Kavanagh J, et al. Vaginal prostaglandin (PGE2 and PGF2a) for induction of labour at term. Cochrane Database Syst Rev. 2014;7(4):CD003101.

18. Zhang Y, Zhu HP, Fan JX, et al. Intravaginal Misoprostol for Cervical Ripening and Labor Induction in Nulliparous Women: A Double-blinded, Prospective Randomized Controlled Study. Chin Med J (Engl). 2015;128(20):2736-2742.

19. Austin SC, Sanchez-Ramos L, Adair CD. Labor induction with intravaginal misoprostol compared with the dinoprostone vaginal insert: a systematic review and metaanalysis. Am J Obstet Gynecol. 2010;202(6):624.e1.

20. Górnisiewicz T, Jaworowski A, Zembala-Szczerba M, et al. Analysis of intravaginal misoprostol $0.2 \mathrm{mg}$ versus intracervical dinoprostone $0.5 \mathrm{mg}$ doses for labor induction at term pregnancies. Ginekol Pol. 2017;88(6):320-324.

21. Khan RU, El-Refaey H, Sharma S, et al. Oral, rectal, and vaginal pharmacokinetics of misoprostol. Obstet Gynecol. 2004;103(5 Pt 1):866-870.

22. Alfirevic Z. Oral misoprostol for induction of labour. Cochrane Database Syst Rev. 2014;2000(4):CD001338.

23. Döbert M, Brandstetter A, Henrich W, et al. The misoprostol vaginal insert compared with oral misoprostol for labor induction in term pregnancies: a pair-matched case-control study. J Perinat Med. 2018;46(3):309-316.

24. Coste Mazeau P, Catalan C, Eyraud JL, et al. Cervical ripening after previous cesarean section with dinoprostone vaginal insert. Gynecol Obstet Fertil Senol. 2017;45(2):77-82. 
25. Alfirevic Z, Aflaifel N, Weeks A. Oral misoprostol for induction of labour. Cochrane Database Syst Rev. 2014;13(6):CD001338.

26. Salim R, Zafran N, Nachum Z, et al. Single-balloon compared with double-balloon catheters for induction of labor: a randomized controlled trial. Obstet Gynecol. 2011;118(1):79.

27. Sayed Ahmed WA, Ibrahim ZM, Ashor OE, et al. Use of the Foley catheter versus a double balloon cervical ripening catheter in pre-inductioncervical ripening in postdate primigravidae. J Obstet Gynaecol Res. 2016;42(11):1489-1494.

28. Hoppe KK, Schiff MA, Peterson SE, et al. 30mL Single- versus $80 \mathrm{~mL}$ double-balloon catheter for pre-induction cervical ripening: a randomized controlled trial. J Matern Fetal Neonatal Med. 2016;29(12):1919-1925.

29. Fruhman G, Gavard JA, Amon E, et al. Tension compared to no tension on a Foley transcervical catheter for cervical ripening: a randomized controlled trial. Am J Obstet Gynecol. 2017;216(1):67.e1-67.e9.

30. De Bonrostro Torralba C, Tejero Cabrejas EL, Marti Gamboa S, et al. Double-balloon catheter for induction of labour in women with a previous cesarean section, could it be the best choice? Arch Gynecol Obstet. 2017;295(5):1135-1143.

31. Kehl S, Weiss C, Rath W. Balloon catheters for induction of labor at term after previous cesarean section: a systematic review. Eur J Obstet Gynecol Reprod Biol. 2016;204:44-45.

32. McMaster K, Sanchez-Ramos L, Kaunitz AM. Evaluation of a Transcervical Foley Catheter as a Source of Infection: A Systematic Review and Meta-analysis. Obstet Gynecol. 2015;126(3):539-551.

33. Mundle S, Bracken H, Khedikar V, et al. Foley catheterisation versus oral misoprostol for induction of labour in hypertensive women in India (INFORM): a multicentre, open-label, randomised controlled trial. Lancet. 2017;390(10095):669-680.

34. Tavares MV, Domingues AP, Nunes F, et al. Induction of labour vs. spontaneous vaginal delivery in twin pregnancy after 36 weeks of gestation. J Obstet Gynaecol. 2017;37(1):29-32.

35. Jonsson M. Induction of twin pregnancy and the risk of caesarean delivery: a cohort study. BMC Pregnancy Childbirth. 2015;15:136.

36. De Castro H, Haas J, Schiff E, et al. Trial of labour in twin pregnancies: a retrospective cohort study. BJOG. 2016;123(6):940-945.

37. Mei-Dan E, Asztalos EV, Willan AR, et al. The effect of induction method in twin pregnancies: a secondary analysis for the twin birth study. BMC Pregnancy Childbirth. 2017;17(1):9.
38. Patabendige M, Jayawardane A. Foley catheter for cervical priming in induction of labour at University Obstetrics Unit, Colombo, Sri Lanka: a clinical audit with a patient satisfaction survey. BMC Res Notes. 2017;10(1):155.

39. Boyon C, Monsarrat N, Clouqueur E, et al. Cervical ripening: is there an advantage for a double-balloon device in labor induction? Gynecol Obstet Fertil. 2014;42(10):674-680.

40. Kehl S, Ziegler J, Schleussner E, et al. Sequential use of double-balloon catheter and oral misoprostol versus oral misoprostol alone for induction of labour at term (CRBplus trial): a multicentre, open-label randomised controlled trial. BJOG. 2015;122(1):129-136.

41. Kehl S, Weiss C, Dammer U, et al. Double-balloon catheter and sequential oral misoprostol versus oral misoprostol alone for induction of labour at term: a retrospective cohort study. Eur J Obstet Gynecol Reprod Biol. 2016;204:78-82.

42. Schoen CN, Grant G, Berghella V, et al. Intracervical Foley Catheter With and Without Oxytocin for Labor Induction: A Randomized Controlled Trial. Obstet Gynecol. 2017;129(6):1046-1053.

43. Levine LD, Downes KL, Elovitz MA, et al. Mechanical and Pharmacologic Methods of Labor Induction: A Randomized Controlled Trial. Obstet Gynecol. 2016;128(6):1357-1364.

44. Connolly KA, Kohari KS, Rekawek P, et al. A randomized trial of Foley balloon induction of labor trial in nulliparas (FIAT-N). Am J Obstet Gynecol. 2016;215(3):392.e1-392.e6

45. Zenzmaier C, Leitner H, Brezinka C, et al. Maternal and neonatal outcomes after induction of labor: a population-based study. Arch Gynecol Obstet. 2017;295(5):1175-1183.

46. Duro-Gómez J, Garrido-Oyarzún MF, Rodríguez-Marín AB, et al. Efficacy and safety of misoprostol, dinoprostone and Cook's balloon for labour induction in women with foetal growth restriction at term. Arch Gynecol Obstet. 2017;296(4):777-781.

47. Bala A, Bagga R, Kalra J, et al. Early versus delayed amniotomy during labor induction with oxytocin in women with Bishop's score of $>6$ : a randomized trial. J Matern Fetal Neonatal Med. 2017;9:1-8.

48. Garcia-Simon R, Montañes A, Clemente J, et al. Economic implications of labor induction. Int J Gynaecol Obstet. 2016;133(1):112-115.

49. Oros D, Garcia-Simon R, Clemente J, et al. Predictors of perinatal outcomes and economic costs for late-term induction of labour. Taiwan $J$ Obstet Gynecol. 2017;56(3):286-290. 